\title{
Regulatory inspection and the changing legitimacy of health and safety
}

Article

Accepted Version

Almond, P. and Esbester, M. (2018) Regulatory inspection and the changing legitimacy of health and safety. Regulation and Governance, 12 (1). pp. 46-63. ISSN 1748-5991 doi:

https://doi.org/10.1111/rego.12155 Available at https://centaur.reading.ac.uk/70105/

It is advisable to refer to the publisher's version if you intend to cite from the work. See Guidance on citing.

To link to this article DOI: http://dx.doi.org/10.1111/rego.12155

Publisher: Wiley

All outputs in CentAUR are protected by Intellectual Property Rights law, including copyright law. Copyright and IPR is retained by the creators or other copyright holders. Terms and conditions for use of this material are defined in the End User Agreement.

\section{www.reading.ac.uk/centaur}

\section{CentAUR}

Central Archive at the University of Reading

Reading's research outputs online 


\title{
Regulatory inspection and the changing legitimacy of health and safety
}

\begin{abstract}
The regulation of conduct via law is a key mechanism through which broader social meanings are negotiated and expressed. The use of regulatory tools to bring about desired outcomes reflects existing social and political understandings about institutional legitimacy, the meanings attached to regulation, and the values it seeks to advance. But these contextual understandings are not static, and their evolution poses challenges for regulators, particularly when they reflect political framing processes. This paper shows how inspection has been reshaped as a tool within the United Kingdom's health and safety system by changes in the meanings attached to the concept of riskbased regulation'. While rates of inspection have fallen dramatically in recent years, the nature and quality of inspection have also been fundamentally reshaped via an increasingly procedural and economically-rational 'risk-based' policy context. This has had consequences for the transformative and symbolic value of inspection as a tool of regulatory practice.
\end{abstract}

Keywords: regulation; inspection; framing; legitimacy; social meaning.

\section{Introduction: Inspection as a regulatory tool}

The proactive inspection of premises has a long history as a regulatory tool. It is widely viewed as having preventive value as a source of information about hazards, symbolic value as a signal of the responsiveness and legitimacy of regulators (Hawkins 2002; Hutter 1997), and instrumental value as a source of deterrence and a driver of managerial focus on regulatory outcomes (Mendeloff \& Gray 2005; Thornton et al. 2005). The existing regulatory literature has identified that processes of regulatory inspection are highly variable in practice, differing according to the 
degrees of formalism, coerciveness, intensity, discretion, and prioritisation used (Black \& Baldwin 2010; Lo et al. 2009; May \& Winter 2000; McAllister 2010; Pires 2011; Sparrow 2000). In addition, local conditions (resources, time, political pressure, communication barriers) also lead to variations in the way that inspections occur (Hutter 1997; Mascini \& van Wijk 2009; McAllister 2010). And profound disagreements still remain over the value of regulatory inspection, which is often characterised as intrusive, unreasonable, and inefficient by critical policy commentators (for discussion, see Almond 2015; Pires 2011; Tombs \& Whyte 2013). The way that regulatory inspection is used by different regulatory agencies has also changed significantly over time as the dominant conceptual model of regulation has shifted away from state-led command-and-control, and towards more responsive (Ayres \& Braithwaite 1992), decentred (Black 2008), and 'smart' (Gunningham \& Grabosky 1998), governance-based formations that allow more room for selfregulation.

These dominant policy models bring new ways of conceptualising the role of inspection (as a matter of reintegrative shaming, enforcement pyramids, or riskbased regulation: Mascini 2013; 2016) and the values it should conform to; as a matter of underwriting processes of regulation that occur beyond the state, rather than as a direct means of exercising control over business behaviour. But these policy conceptualisations are themselves variable and subject to reinvention, particularly in response to broader changes in policy narratives. For example, as this paper will demonstrate, 'risk-based inspection', that is, the quantitative targeting of inspections and regulatory resources at points of greatest impact and efficacy (Hutter 2005), has been a feature of the regulatory landscape for many years, but its meaning has not remained static. Instead, it has been a conduit through which different social meanings have been expressed in accordance with the changing political context, and has come to embody that changed context in new ways. This paper will document the ways in which risk-based inspection has been recast in different forms at different times, arguably becoming more economically-rational and discriminating, and these changing versions of 'risk-based' practice have created "new orthodox[ies]" of social meaning (Lessig 1995: 948) attaching to inspection as a practice. These orthodoxies emerge in response to the social and political pressures that regulators face, including their ideological grounding, operational constraints, 
and needs to demonstrate legitimacy (Baldwin \& Black 2016: 566). At the same time, they also embed broader values, which valorise state minimalism and economic modes of thought, more deeply within the regulatory sphere. This process of social meaning-construction places significant demands upon regulatory actors, as external agendas that reflect a commitment to economic decision-making conflict with the ways in which those agencies conceive of their own role and purpose.

This investigation draws on one example of just such a trend in practice, that of occupational health and safety inspection in the United Kingdom, which has been utilised since 1833 (Almond 2013: 99; Rhodes 1981). Inspection practices in this arena changed radically in 1972, when a major Government-commissioned policy review of workplace health and safety regulation (the 'Robens Committee') found inspection to be the "main day-to-day activity of the majority of inspectors", but also often "brief, superficial, and...unproductive" in practice (Robens 1972: paras.201; 218). The subsequent Health and Safety at Work Act 1974 established the Health and Safety Executive (HSE) as the UK's national regulator, whose inspectors were empowered to undertake the targeted 'examination and investigation' of workplaces. Subsequent research outlined the decision-making processes and strategic considerations that underpin HSE's use of inspection (Hawkins 2002; Hawkins \& Hutter 1993; Hutter 1986; 1989; 1997; Hutter \& Lloyd-Bostock 1990). But, despite being an early adopter of what would come to be known as 'risk-based' practice, HSE has subsequently been subject to numerous policy reviews, resource cuts, and much hostile media coverage (Almond 2009; 2015; Walters et al. 2011: ch.8). This has impacted upon rates of inspection, which halved in the first ten years of HSE's existence (from 481,000 in 1975 to 246,000 in 1985: Dawson et al. 1988: 225), and have continued to fall. In 2013-14, HSE inspected 23,470 premises (HSE 2014a: $11), 10 \%$ of the 1985 total.

The first part of this paper will set out the nature and status of 'risk-based' regulation as a contested policy norm, and the second will identify the mechanism of meaningconstruction that underpins the evolution of policy norms of this sort. It will then go on to outline four different ways of framing risk-based regulation, which have predominated at particular times during the last forty years. They are not necessarily wholly distinct, rather, they are differing, overlapping "structure[s] of knowledge, experience, values, and meanings" (Hawkins 2002: 52) within the 'field' of health and 
safety regulation. Across these periods, the external pressures brought to bear upon regulatory actors have radically altered the reality of inspection, while HSE has remained a committed leader in the use of risk-based models (Hampton 2005). Yet it has also had to negotiate the shifting orthodoxy of meaning around inspection, seeking to remain engaged with the prevailing policy norms of government, while also adapting its practices to a changing external context of demands for 'better regulation'. In particular, the regulator has had to adapt to a policy environment that is increasingly defined in economic terms, highlighting the power of external priorities to reshape regulatory tools that might otherwise be taken for granted.

\section{A 'regulatory ideal' of risk-based inspection?}

The Robens Report (1972) was one of the first Governmental policy documents to advance the new 'ideal' of regulatory inspection, whereby '[t]he primary objectives...should be first, to support [the] development [of self-regulatory capacity]; and secondly, to concentrate regulatory resources more selectively on serious problems" (1972: para.216). This was an early version of a 'risk-based' strategy, entailing "the development of decision-making frameworks and procedures to prioritise regulatory activity and the deployment of resources...[via] an assessment of the risks that regulated firms pose to the regulator's objectives" (Black 2005: 516). Following the example of 'early adopters' such as HSE, risk-based regulation gained traction during the 1980s in response to political demands for greater accountability and efficiency in the use of public resources (Hood 1991; Hutter 2005: 5; Rothstein et al. 2013: 220). This was an era when the methodology of quantitative risk management, as a means of ensuring the resilience of systems and institutions in the face of future events, became widespread within financial markets. Systematic risk management came to be utilised generally as a means of ensuring sustainable 'good' governance, and also as a tool for the exploitation of risk as a source of financial benefit, for instance, via hedge-funds and derivatives markets (Bernstein 1996; Kloman 1990; Power 2007). Partly this reflected notions of a 'risk society', characterised by social and technological change, where problems are increasingly defined in terms of risk. Partly, also, it reflected the compatibility of risk-management approaches with the political valorization of individual responsibility and the marketization of risk (O'Malley 2004; Power 2007). 
Risk-based approaches to regulation are one manifestation of this broader diffusion of risk-management techniques as a mode of governance. Because of their focus on providing technical, 'objective' responses to social problems, risk-management approaches have come to be seen as a means of demonstrating the authority, credibility, and legitimacy of those who utilise them (O'Malley 2004: 296-7; Power 1997: 76; Sparrow 2000). Undertaking interventions which are targeted according to predetermined risk criteria allows the management of risk to be presented as part of a conscious, willed strategy of control (Black 2005: 519). In the case of risk-based regulation, this involves applying a suite of tools that go beyond the traditional, statecentred options of inspection and enforcement, and ensuring that their use is directed according to their value in achieving regulatory outcomes (Baldwin \& Black 2016; Black 2005; Black \& Baldwin 2010; Power 2004; Sparrow 2000). On this model, 'risk' (the likelihood and seriousness of a particular harm) guides decisions about resource-allocation. Voluntary and self-regulatory methods are used (selfauditing, third-party accreditation, association memberships, voluntary agreements) where there is sufficient capacity and motivation to suggest that acceptable levels of compliance can be sustained via less intrusive means than state-led inspection (Hampton 2005; Hood et al. 2001). This means that some types of risk-causing behaviour are accepted so long as they occur at levels or in contexts that fall below the thresholds established for intervention (Power 2004: 22; Rothstein et al. 2013). It also offers the possibility of containing the normative conflicts that underpin regulatory policy; by regarding risks as objectively knowable, and utilising evidenceled decision-making processes, regulatory choices can be recast as politically neutral and procedurally legitimate (Rothstein et al. 2013: 218).

Risk-based approaches to inspection have subsequently been painted in some quarters as a norm of contemporary regulatory practice, part of a national and international governmental commitment to 'better regulation' (Cabinet Office 1999; Better Regulation Task Force 2000; OECD 2010: 9.4-5). The UK Treasury's Hampton Review framed its risk-based recommendations as matters of commonsense cost reduction rather than as 'policy choices' (Hampton 2005: 1.76-1.8); as a source of administrative cost, inspection should, de facto, be reduced in favour of greater reliance on the "earned autonomy" of duty-holders (2005: 4). Hampton linked risk-based targeting to the notion of 'responsive regulation' (Ayres \& Braithwaite 
1992; Black \& Baldwin 2010; Gunningham \& Grabosky 1998), advocating the "reallocation of regulatory resources...from expenditures on direct inspection to expenditures on audits of corporate compliance...concentrated on companies that play fast and loose" (Ayres \& Braithwaite 1992: 129). Despite being lauded for its use of risk-based targeting (2005:2.18-2.20), HSE was pushed to reduce its inspection activity further, leading to a post-Hampton drop of $50 \%$ in inspection rates from 2004-2007 (BRE 2008: 22). The 2010-15 Coalition Government further reduced HSE's rates of scheduled inspection by 33\%, seeking "better targeting based on hard evidence of effectiveness" (DWP 2011: 9) and of firms' past performance and safety management systems (BRE 2008: 7).

Despite their endorsement in policy processes of this sort, risk-based approaches have not necessarily achieved the status of a "universal' policy instrument" (Rothstein et al. 2013: 216; also Hutter 2005; Baldwin \& Black 2016). The interpretation of risk varies widely across place and time, and is capable of being interpreted so as to rationalise a wide range of differing models of decision-making. Different regulators interpret and implement it either as a broadly aspirational commitment, a guiding principle for decision-making, or a pervasive set of management strategies and tools, depending upon their legitimatory needs and the institutional risks they face (Black 2005: 521; Baldwin \& Black 2016). Risk-based approaches may be tailored according to whether they are intended to advertise a regulators' responsiveness and limit its political accountability, to implement a process of resource reallocation, or to implement a radically different relationship to the risks being managed (Black 2005: 525; Rothstein et al. 2013: 221). Further, individual regulators alter their own commitment to risk-based thinking over time, using practical risk-based tools at one time as part of their methodology, and at a later time moving to embed the cultural norms that underpin it (Black 2005: 526; Hutter 2005: 5).

Practically, divergent approaches may be taken to the use of risk-based tools. At a fundamental level, important choices must be made about how risks are defined, which will be targeted, and which will not. These choices can be contingent upon the ideological or cognitive frameworks that regulators use, the operational (often resource-based) constraints they are subject to, and the external political legitimacy needs they must fulfil; these three drivers produce considerable variation in 
regulators' embedded practices, shaping how risks are "constructed, packaged, and identified" (Baldwin \& Black 2016: 569). Choices as to whether to prioritise targeting risks to primary stakeholders, secondary risks (to consumer confidence or industry competitiveness), or organizational risks to the regulator (Black 2005: 23), can be politically controversial, as can the quantification of otherwise qualitative factors such as reputation (Black \& Baldwin 2010: 188), and the conflicting procedural legitimacy norms (of consistency and expertise) produced via the systematic application of content-specific, discretionary decision-making (Baldwin 1995: 41-7; Black 2005: 513; Black \& Baldwin 2010: 189). The objectivity of risk-assessment processes can also be contested, both by participants who hold divergent views (Hutter 2005: 9), and by critics who view them as ideological constructs (Tombs \& Whyte 2013).

In sum, 'risk-based regulation' is a concept which bestows political capital, but which is used in relation to often loosely-connected initiatives (Hutter 2005: 3; Power 2004), obscuring significant local and contextual variations in policy and practice (Baldwin \& Black 2016; Rothstein et al. 2006). More particularly, "[r]isk-based frameworks are not neutral, technical instruments" but rather "involve a complex set of choices" about which risks merit attention, how they are measured, and what levels of failure are tolerated (Black \& Baldwin 2010: 185), and so normative disputes about these decisions need resolution via political processes (Rothstein et al. 2006: 1068). But, by being framed narrowly, as instrumental solutions to complex policy issues, concepts such as risk-based (and 'responsive') regulation are 'hollowed out' so as to fit with existing institutional ideals and imperatives (Mascini 2013: 55-6). For HSE, which has utilised risk-based methods for some time, political pressures around issues of 'over-regulation' have required the agency to show its legitimacy via an evolved risk-based approach to inspection (Almond 2015; Walters et al. 2011: 167; Young 2010). Here, as elsewhere, the ostensibly depoliticized risk-based 'orthodoxy' has been a means of achieving political change within a regulatory regime.

\section{The external framing of regulation}

Rather than viewing regulatory approaches as having fixed characters, then, it is necessary to examine the degree to which they are constructed in accordance with broader understandings about the meaning of regulation. Regulatory interventions have an expressive function, in that they make statements about "which values take 
priority over others, or how various values are best understood" (Pildes \& Sunstein 1995: 66), which change according to their context (Lessig 1995: 961). Regulatory strategies are part of a wider project of dialectical meaning-creation deployed, on the one hand, in order to influence existing behaviour, producing desirable outcomes via persuasion and coercion. At the same time, however, they are shaped by the external interests of policy-makers and others who influence the 'framing' of those processes by "select[ing] some aspects" of their "perceived reality and mak[ing] them more salient" (Entmann 1993: 52; also Benford \& Snow 2000). Part of the role of health and safety law, then, is to change social meanings around work, reinforcing notions of acceptable behaviour and attaching penalties to non-compliance (Hawkins 2002: 4; Lessig 1995: 995; Sunstein 1996: 2031). Inspection assures the provision of a public good by changing the incentives and meaning attached to compliance, but also acts as a forum for the expression of prevailing formal values, rendering a particular conception of the role of the state, and of the settlement of competing interests, into legal fact as a new orthodoxy (Lessig 1995: 948).

The expressive dimension of regulation is often envisaged as counterbalancing the dominance of quantitative tools (such as cost-benefit analysis) and economic rationality within regulation (Lessig 1995; 1996; Pildes \& Sunstein 1995; Sunstein 1996). On this view, we should look at wider factors that determine the 'goodness' of a policy, beyond economic utility, by giving effect to issues of value as well as cost. The notion of expressive regulation suggests that the enactment of these values should broaden the scope of the regulatory endeavour away from the pursuit of outcomes which relate purely to economic rationality. But what if processes of expressive law-formation reflect prevailing values which, in fact, privilege precisely this kind of economic-based thinking, entrenching rather than challenging its 'imperialism' (Lessig 1996: 2189)? In such a circumstance, the functional capacity of law communicates norms attaching to conduct, but in pursuit of ends which replace social considerations with more instrumental ones. This is a possibility because, as previously discussed, regulation is often heavily contested; internal values and ideology, the pragmatic economics of resources, and external political values and pressure, all influence the selection and prioritisation of risks, and exert varying degrees of influence at different times (Baldwin \& Black 2016: 593). These drivers also interact in problematic ways, creating conflicts of rationality that pose functional 
and procedural challenges for regulators, who are pulled in multiple directions by these needs, able to satisfy some but not all of them.

As the remainder of this paper will demonstrate, the concept of 'risk-based inspection' has been interpreted in different ways at different times in response to the shifting balance of the three drivers identified by Baldwin and Black (theoretical, operational, and political: 2016). On the one hand, this has been a case of regulatory practices expressing the prevailing external contextual pressures that act upon them as a form of direct, proactive meaning-construction, framing risk-based inspection in different ways in order to reassert the core values that underpin this area of regulatory practice. Inspection is able to serve as an expressive indicator of political priority (Hutter \& Manning 1990; Walters et al. 2011: ch.8), of the importance of the problems regulators seek to resolve (Sparrow 2000: ch.9; Baldwin \& Black 2016), as a barometer of institutional risk (Black 2005; Etienne 2015; Rothstein et al. 2013), and as an embodiment of particular conceptions of the relationship between private actors and the state. This does not occur solely via the quantitative number of inspections undertaken; the qualitative character of inspections (what is looked at) is just as important a source of meaning. It would be too simplistic to assert that a reduction in inspection numbers meant there has been a fundamental change in regulatory policy, but, alongside other indicators, it does highlight the changing meaning expressed by risk-based inspection, and the shift towards the expression of instrumental norms over time.

On the other hand, however, the changing definition and use of risk-based inspection is also a result of regulators choosing to utilise this concept reactively, in response to the external pressures they face, as a means of showing their conformity to a broader 'orthodoxy of meaning' which valorises the values that this regulatory tool is seen to embody. Being 'risk-based' is an effective means of demonstrating a response to those pressures because it resonates with the values that Governmental policy actors in the United Kingdom have repeatedly endorsed, namely, that public preferences and interests are actually best served via a conception of the regulatory 'good' that is avowedly economically rational in nature (Almond 2015; Tombs \& Whyte 2010), as this reinforces values of self-reliance, non-interference, and antiinterventionism. Rather than transcending or challenging economic modes of thinking, the casting of law in expressive terms is thus utilised as a means of 
advancing a deeper policy norm of economic rationality. On this view, the agency of regulators as creators of new orthodoxies of meaning is offset by their effective capture by broader policy orthodoxies. The remainder of this article outlines four different understandings of risk-based inspection that have emerged at different times, and the ways in which the expressive meanings attached to risk-based inspection have been redefined so as to increasingly embed an economic approach to regulation.

\section{Methodology}

A mixed-methodology approach was utilised to gather a historical overview of the way that the legitimacy of health and safety has changed in the UK over the last 60 years. In order to generate original insights into historical processes, semi-structured oral history interviews were undertaken $(n=40)$ during 2014-15 with key actors from the recent history of health and safety, recruited purposively due to their specific contribution, reputation, and role within the field. The range of interviewees was balanced to ensure that multiple constituencies (regulators, policymakers, trade unions, safety professions, and employers) were represented. They were conducted 'on-the-record', audio-recorded and then transcribed so as to render them as oral history documents; these transcripts were subject to analysis via an iterative process of descriptive coding. Interviewees were given significant scope to self-direct their contributions within the context of a framework of prepared questions and issues for discussion. ${ }^{1}$ In order to contextualise this data, and offset any possible tendency for interviewees to exert bias in their recollections, a wide range of historical, archival, and written documentary sources were also surveyed and analysed. Although some documents have not survived, and others under 30 years old are subject to access restrictions, materials produced by state bodies, trades unions, employers' organizations, workers, the media, and non-governmental organizations, were obtained. Documents were initially sampled by availability to gain a broad overview, followed by more concentrated investigation of areas that emerged as being of particular importance.

\footnotetext{
${ }^{1}$ All but two interviewees gave their consent to be interviewed 'on the record', however, to improve accessibility, when interviews are referenced in the text, they are identified in parentheses via a descriptor of the interviewee's most relevant role, the time period when they were active, and the relevant paragraph in the interview transcript.
} 


\section{The First Frame: Risk and Expertise}

The inspection of premises to share expertise with, and provide specialized support to, regulated firms, was central to the relational, knowledge-centric pre-Robens regulatory system:

"Our district inspector...[had] a thirst for knowledge. Over and over again, he'd ring me up and say 'is it all right if we come down to the works? I'm not here inspecting, I just want to see that particular plant'." (Steel Industry Safety Professional, 1950s-1990s: para.14)

Similarly, former Factory Inspectors recalled the day-to-day process of visiting the premises on their 'beat', and getting a feel for the risks present:

"I spent five years in the backstreets...just one factory next to another...plating and polishing and grinding... We kept records of every machine, we visited by surprise and even if they'd stopped the machine you could feel it was hot." (HSE Chief Inspector of Factories, 1970s-1990s: para.8; also HSE Chief Inspector of Factories, 1980s-2000s: para.25)

Inspection was a tool of regulatory 'craft' (Sparrow 2000), underpinned by finegrained expertise derived from frontline experience, and deployed within relationships based on goodwill, but the Factory Inspectorate lacked the resources needed to be able to claim completeness of coverage (DEP 1968: xi). The expansion of the regulated sphere to include non-factory workplaces during the 1960s and 1970s meant selectivity was required, usually on the basis of company size and sector (Rhodes 1981: 85), but wedded to a standardized inspection programme:

"under the Factories Act, it didn't matter if you were Ford Motors employing thousands...or a little furniture place in the East End, you would be inspected every four years on a mechanical rota basis." (HSE Chief Inspector of Factories, 1980s-2000s: para.27)

The 1972 Robens Report argued that, while in the past it may have been desirable to "dip...into each establishment from time to time", the changing risk environment meant that inspections should be targeted at issues "identified through the systematic assessment of all the available data" (1972: paras.217-8). This prompted HSE to become, in 1977, one of the first regulators to shift to the use of a form of risk-based inspection (Hutter 2005): 
"We abandoned the four yearly cycle once we'd got the '74 Act, became much more risk-based in our approach, and Inspectors began to assess firms by their ability to manage safety... That enabled us to free Inspectorate resources to concentrate on riskier enterprises". (HSE Chief Inspector of Factories, 1980s-2000s: para.28)

The 1974 Act placed a greater emphasis on safety management as the basis of compliance, necessitating more systemic inspection practices with a greater focus on 'management competence' (HSE 1980: v; Walters et al. 2011: 175-7). Alongside this, there were institutional biases towards focusing regulatory expertise on particular sectors where it was thought that a 'high-risk' approach was merited; this had self-fulfilling tendencies, however, as the issues present in the sectors deemed 'low-risk' were neither viewed as a priority nor an area where gains were expected (Hutter 1997: 39), reinforcing the hierarchies inherent in risk-based targeting. This was observed in relation to 'new entrant' industries like retail and office-work:

"There was a tendency to put people who were less effective...into the less important' new-entrant activities...there was an unwillingness to recognise that there were things we had to learn" (HSE Deputy Chief Inspector of Railways 2002-2010s: paras.97-101)

At the same time, however, the "available data" that Robens felt should inform riskbased targeting also included "local knowledge" (1972: para.218). 'Risk' was thus reflective of professional expertise (Hutter 1986: 117), "plac[ing] a high value on the judgement of inspectors", and advertising this expertise to the regulated population (Warburton 1980: 8). As a new regulator, made up of previously-independent Inspectorates, HSE had an internal need to embed consistency among its staff; but it also had an external need to differentiate itself from Robens' criticisms and establish itself as competent in the eyes of Whitehall (HSE Chief Inspector of Factories, 19701990s: para.35; HSE Director-General, 1980s-1990s: para.40). This particular need was tied to the kind of legitimacy pressures identified by Baldwin and Black (2016) as a driver of risk-based practice; the need to show competence and meet expectations. There was relatively little pressure from Government to reduce the costs of regulation; rather, the prevailing political driver was towards an improvement 
in performance (in terms of accident rates: Robens 1972: paras.17-18). ${ }^{2}$ The choice of this approach was thus a political one, centred on the prevailing external pressures that the regulator was facing. 'Risk-based' inspection was not a predefined approach that HSE was pushed to adopt, but rather one it developed itself, refocusing the work of the skilled Inspectors and supporting rather than undermining their professional status:

'The reorganization of the inspectorate... was to meet Robens' criticism that there was insufficient informed inspection. Inspectors had to be more expert and this specialisation enabled inspectors to concentrate on what they really knew about." (HSE Chief Inspector of Factories, 1970s-1990s: para.37)

The skilled, scientific, technical categorisation of risk was utilised as a means of responding to these external legitimacy needs; framing inspection as a matter of expertise gave primacy to the cognitive and theoretical drivers of risk-construction, offering HSE a strong narrative about its approach and values. 'Risk-based' inspection expressed an image of expertise and competence which underpinned HSE's organizational legitimacy (Baldwin 1995: 45; Warburton 1980) and reinforced the values it espoused (Sunstein 1996: 2032). Systematic risk-based targeting allowed for the uneven distribution of expertise and inspection, utilising them where they might be most effective, while continuing to frame them as universal regulatory 'goods', demonstrating both effectiveness and an inclusive form of control (Rhodes 1981: 91). It underlined the social authority which was needed to establish new cultural norms around the relationship between law and the workplace, at a time when the regulator, the regulatory framework, and the idea of formal safety management, were new and unfamiliar. As Hutter observed, "The very physical presence of a regulatory official serves...to emphasise that official's authority of office and remind the regulated of the existence of regulatory laws" (1986: 122).

\section{The Second Frame: Risk and the New Public Management}

Having deployed its expertise to establish itself as an expert, risk-based regulatory agency, HSE expanded rapidly, growing from around 400 staff at the start of the 1960s to 4700 by the end of the 1970s (Dawson et al. 1988: 217). At the same time,

\footnotetext{
2 See The Times, 'Accidents caused by unguarded minds', 31 January 1973, p.7; Times, 4 April 1974, p.16; Times, 22 May 1978, p.8.
} 
regulation was acquiring an increased political profile as a new vision of government took hold, particularly in newly-privatized sectors (Moran 2003), and becoming more contested in principle, particularly in areas where its welfarist origins clashed with the prevailing liberal-market political climate of the time (Dawson et al. 1988; Hutter \& Manning 1990: 107; Moran 2003):

"Several strands of political phobia became entangled...These were (1) dislike of "European" interference in "British" law; (2) the idea of the "nanny state"; (3) the traditional Tory dislike of "burdens on business" and susceptibility to the views of small companies" (HSE Director-General, 1980s-1990s: para.66).

This political pressure emphasised the balancing of regulatory goals against competing economic demands, and a desire to 'roll back' the state, leading to a shift towards what political scientists have called the 'New Public Management' (or NPM: Hood 1991). This approach sought greater constitutional legitimacy (accountability and efficiency) in the public sector, via the creation of a culture of 'managerialism', the setting of performance targets, the introduction of private-sector involvement, and greater fiscal discipline. This contributed to a shift in the way that government operated, with reduced state provision being accompanied by a proliferation of arm's-length regulatory controls focused on secondary 'framework' oversight rather than primary delivery (Hood et al. 2001; Moran 2003: 5; Pires 2011).

For regulators, this pressure to pursue the goals of the "free economy and the strong state" (Gamble 1994) made risk-based approaches expedient. Government reviews, including the White Papers Lifting the Burden (HM Government 1985) and Building Businesses...Not Barriers (HM Government 1986), highlighted the perceived disadvantages of regulation, recommending fewer routine inspections. For HSE, this reinforced its existing approach (Dawson et al. 1988: 234; Hutter 1986: 116; 1997: 110), whereby Inspectors used a computerized Inspection Rating System to determine, for each business:

"what the standard of health was, what the standard of safety was and what the standard of welfare was, and they gave values from 1 to $5 \ldots$ Then they would judge, if the worst happened at the factory, would nobody be killed, would one person be killed, or would more than one person be killed?... The last question was 'what confidence have I got in management's ability to maintain standards?', that was given a figure. When you multiplied these 
figures they gave a value between 1 and 100...add up the rating values for every factory across the country and divide that total by the available number of 'Inspector half-days' to give a value above which we should aim to inspect...That came out initially at 42." (HSE Chief Inspector of Factories, 1970s-1990s: para.31)

Risk was understood here to be 'responsive', constructed according to behavioural, institutional, and cultural factors (Black \& Baldwin 2010: 186), as well as the nature of the hazard itself. One manifestation of this was the embedding of a self-regulatory approach. Formal risk assessment requirements were introduced via the Management of Health and Safety at Work Regulations (1993); safety management systems (encompassing policy, monitoring, and audit) were promoted via publications like HSE's 'Successful Health and Safety Management' guide (1997); and safety case regimes were introduced for complex industries in the late 1980s. Together, these mechanisms moved responsibility for many of the functions of inspection onto the regulated (Gunningham \& Johnstone 1999: 118; Hutter 2005: 7; Walters et al. 2011: 176-7), with inspection a secondary measure applicable in a narrower range of cases.

Risk was also understood holistically, meaning that other contextual factors, such as social utility, public concern, and cost, also factored into the targeting of interventions. The Tolerability of Risk Framework (HSE 1988) was developed to assist in balancing competing concerns around high-hazard industries such as nuclear power, allowing HSE to systematically weigh calculations of risk and the feasibility of control alongside judgements about the utility and acceptability of those risks (as 'broadly acceptable', 'tolerable', or 'unacceptable'). 'Tolerable' risks are permissible "provided [they are] made as low as reasonably practicable... Where the risks are less significant, the less, proportionately, it is worth spending to reduce them and at the lower end...it may not be worth spending anything at all" (HSE 1988: paras.35-7). These calculations helped manage the objections of sceptical constituencies, partly because they allowed for explicit trading-off of cost and benefit, and partly because they allowed decision-makers to frame contested policy issues in a more objective form (Hutter 2005: 6). Risk-tolerance was thus framed via reference to contextual factors: 
"There is a scientific professional process of assessing how big a risk it is, but in the end it's a political judgement where you draw the line between what level of risk is tolerable and what is intolerable...you're not saying risk is acceptable, you're saying you'll tolerate some small areas of risk." (HSE Director of Medical Services, 1980s-1990s: para.132)

The adoption of risk-based methodologies fitted with the Government's 'NPM'inspired policy initiatives, but it is noticeable that the element of this approach which most influenced the framing of inspection at this time was that of budgetary restraint. Baldwin and Black identify operational constraints of this sort as one of the key drivers of risk identification (2016: 573). At the start of the 1980s, the Chief Inspector of Factories, in his Annual Report, recognized that, in light of a $6 \%$ budget cut, "what the Factory Inspectorate can achieve is obviously constrained by the resources at its disposal", and so cost-benefit analysis would determine where inspection could be applied (HSE 1981: v-vii). This was a significant departure from the more expansive resource context of the preceding decade. The problem was that the 'value' of inspection was extremely hard to assess (Hawkins 2002: 284-9; Sparrow 2000: 113115), meaning that it had to be taken 'on faith' (Rhodes 1981: 87-91). Throughout the 1980s, HSE repeatedly debated the trading-off of inspection in pursuit of efficiency (Dawson et al. 1988: 231-3). By 1988, HSE's Director-General was telling Parliament that "[o]ne really has got to decide if one can afford [the] scale of diversion of one's resources" that more inspections would entail, and that "[w]e would not think it necessary to waste a lot of time on a great many of the premises" this would involve (Employment Committee 1988: paras.18, 23). This resulted in the imposition of government targets to ration inspection:

"IIt] was the first time that HSE had ever been set targets...the Treasury saying, very clearly, 'we grant you these resources every year, we've got to have measures in place which enable us to see how you're contributing...you have to have [targets], if you don't, we'll come up with the targets for you'." (HSE Policy Advisor, 1980s-2000s: paras.47-8)

In this second frame-period, we see a move from a model of risk-based inspection centred on expertise, to one shaped in terms of capacity; fiscal operational pressures led to a need to balance activity in order to obtain the greatest value from HSE's dwindling resources. On one level, HSE was remaining consistent in its approach, 
building on the 'Robens ideal' of enforced self-regulation, but finding itself constrained by the managerial and financial risk drivers of central Government policy. The concept of risk was thus deployed as a means of managing these demands and showing accordance with operational imperatives, and the fitness necessary to survive in a hostile policy environment. But on the other hand, the capacity-based logic of this position was a direct component of HSE's institutional 'license to operate'; economic policy plays a major part in determining how a regulator should prioritise its resources (Black \& Baldwin 2010: 195-7). Political support was contingent upon HSE demonstrating parsimony and a commitment to the terms of the NPM, and so risk-based targeting became a means for the agency of communicating not about its credentials, but about its essential compatibility with the broader political agenda of the time. In doing so, HSE had to internalise an overarching economic orthodoxy that was imposed from the outside, and entrench it by rendering its other aims secondary to a view of regulation as, at its core, a 'numbers game', which HSE was willing to "play hard" (British Nuclear Group, Chief Operating Officer, 1990s-2010s: para.20).

\section{The Third Frame: Risk and Risk-Activism}

One conclusion that might be drawn from the preceding discussion is that risk-based inspection is an inherently deregulatory mechanism. But it also generates other dynamics, by refocusing attention onto specific problems and areas of risk, and away from others. Like 'responsive' regulation, which emphasises the need to react to changes in behaviour and context (Ayres \& Braithwaite 1992), risk-based targeting of inspection directs resources to points of concern, depending on what outcomes matter to the regulator, and what appetite for risk they possess (Baldwin \& Black 2016; Black \& Baldwin 2010: 184; Rothstein et al. 2013: 217; Sparrow 2000). The Labour Government of the late-1990s took a proactive interest in health and safety:

"The Deputy Prime Minister...wanted far more inspections...a far stricter regime, and...to be in charge of everything. That was a different kind of challenge, it wasn't one of, 'let's cut the resources, let's undermine the regulation', it was the opposite. But in many ways just as dangerous" (HSE Director-General, 1990s-2000s: para.45).

This led to some increase in resourcing (Walters et al. 2011: 184), a commitment to the criminalisation of work-related deaths (Almond 2013), and a new 'Revitalising 
Health and Safety' strategy (DETR 2000), which sought to "inject new impetus to better health and safety in all workplaces" (DETR 2000: 1) by setting targets for reductions in the numbers of fatalities, injuries, ill-health cases, and working days lost, by 2010. 'Revitalising' proposed that inspections should "promot[e] better working environments" and a "more deeply ingrained culture of self-regulation" (2000: 18) by focusing upon the most commonplace aggregated risks (such as 'slips, trips and falls' and 'lifting accidents'), a 'problem-oriented' approach (Sparrow 2000: 123-136) that was expected to greatly reduce outcome rates.

While Revitalising continued the NPM's concern with issues of performancemanagement, it also sought to exercise control in line with organizational strategy:

"[S]ome inspectors were basically doing what they wanted, it wasn't obvious there was a clear rationale...'No inspection without a reason' did mean concentrating on certain areas...strengthening the Construction Inspectorate, high-level engagement involving myself and [the Deputy Prime Minister]." (Health and Safety Commission [HSC] Chair, 1990s-2000s: paras.71-75)

Construction attracted attention as the late 1990s and early 2000s was an era of major growth in this industry due to the proliferation of public-private funding for major capital projects, and this gave HSE an opportunity to access a large, visible, highly-unionized industry with a poor safety record, which provided a symbolic forum for political engagement with safety issues:

"That was a time when perceptions loomed large...[The] Secretary of State convened a roundtable to see what might be done to improve matters within construction. The challenge was to get the smaller operators engaged." (Government Minister, Department of Work and Pensions, 2000s: para. 24)

Construction is a networked industry, dominated by a small number of major players who employ a larger number of sub-contracting smaller firms, who in turn interact with the 'minnows' who make up the rest of the industry (Hawkins 2002: 126-134; Pires 2011). This was ideal for the development of a "trickle-down" approach to regulation (Construction Company Chief Executive, 1970s-2010s: para.28), utilising 'soft' power mechanisms such as voluntary target-setting, inter-firm pressure, and tendering requirements (something not unique to the UK: Pires 2011). In this model, inspection is used in a limited number of cases, to fulfil strategic engagement goals (Gunningham \& Johnstone 1999: 129-133). HSE used inspection 'blitzes' to raise its 
profile in the industry (House of Commons 2004: 7), underlining the status of inspection as an 'activist' measure:

"We started knocking on the doors of Chief Executives...we changed our performance metrics from simply counting inspections to placing more emphasis on delivering outcomes. Over a 5-year period, we reduced the number of inspections by $50 \%$ and the fatal accident rate went down by about $50 \%$ as well." (HSE Chief Inspector of Construction, 1990s-2000s: para.28)

Safety regulators also became more activist, taking 'ownership' of a wider range of issues, which some saw as antithetical to risk-based principles:

"[HSE] rather lost the ability to understand that it would do better to concentrate on a small number of things that mattered in any given area as opposed to telling everybody how to do everything. It moved into that mode in the 1990s and the early 2000s." (Senior HSE Source, 2000s-2010s: para.31)

Others saw this expansion as a result of the changing workplace context:

"Things like carpal tunnel syndrome...that go with the changing nature of the labour market...[were] the kinds of issues we were dealing with on health and safety. And that was [a source] of Ministerial suspicion. Why did you need to have any kind of regulation at all in these areas?" (HSE Director-General, 1990s-2000s: para.77)

The target-based Revitalising approach was developed further via an implementation strategy known as 'Fit3' ('Fit for Work, Fit for Life, Fit for Tomorrow'3: Prosser 2010: 96). Fit3 sought to address areas of quantitative concern, and continued the principle of Revitalising by making risk-based inspection practices more problem-focused, but also 'aimed low' (Black \& Baldwin 2012), in that the application of quantitative principles (frequency, cost, availability of gains) meant that low-hazard, highfrequency issues were given high priority (Walters et al. 2011: 200-2). The problem with Fit3 was that it narrowed the discretionary scope of inspection (Walters et al. 2011: 208), creating:

"a disconnect between what [we] were being told were priorities and what the inspectors themselves wanted to do...walking into a workplace, seeing something that looked not quite right but wasn't [a Fit3 priority] didn't sit very well." (HSE Inspector, 2000s/Trade Union Official, 2000s-2010s: paras.62-4)

\footnotetext{
${ }^{3}$ http://www.hse.gov.uk/aboutus/strategiesandplans/hscplans/businessplans/0506/fitfor.htm
} 
Fit3 was ultimately abandoned because it conflicted with the cognitive drivers that were central to the organisation's professional culture (Black \& Baldwin 2012: 14), and with broader regulatory orthodoxies around what 'risk-based' was supposed to mean (Tombs \& Whyte 2013: 72). Although 'risk' reflects calculations of 'hazard $x$ probability', most policy literature uses it as a synonym for 'high hazard/low frequency', rather than 'low hazard/high frequency' (Black \& Baldwin 2012). 'Riskbased' inspection is thus envisaged as the narrow application of attention to acute cases, rather than the broad application of attention to low-hazard workplaces (Hampton 2005; DWP 2011). Fit3 turned this pyramid on its head, marginalising the cognitive tradition of risk-based targeting and centralising a more communicative set of drivers reflecting governmental aspirations for this area; HSE sought reputational benefit via the adoption of a more activist approach (Baldwin \& Black 2016: 578). But rather than conflicting with the rationalised regulatory orthodoxy that the NPM had embedded, this activist frame actually continued that trajectory of development, because the activist goals pursued remained subservient to a commitment to economic thinking. Fit3 was undone, in the end, by HSE's inability to show a positive effect on the 'outcome measures' it was using (Walters et al. 2011: 205), so the agency went to "great lengths to bury" it:

"[HSE] never tested their interventions by saying, 'if we did this, would it actually work?' They simply assumed if you put more resources into more inspections then there would be improvement...the figures didn't move at all...[Inspectors] thought it was rubbish, and they were right." (Senior HSE Source, 2000s-2010s: para.70)

The framing of inspection as a tool of 'risk-activism', though not obviously 'deregulatory', played a key role in creating a new orthodoxy of meaning. Inspection was deployed as a lever of change, to be used symbolically in response to political and communicative concerns, but was still measured in terms of the economicallybased assessment of its instrumental impact. This meant that the value of inspection, in terms of the communicative drivers directing it, was not measured at all; instead, a completely different set of norms and expectations were referenced at the evaluation stage, and it was on these measures that inspection, and Fit3, were seen to have failed. This disjunction can be seen in the fact that, while HSE normally avoids quantifying the value of inspection (House of Commons 2008: Ev.284), it 
cited its instrumental ineffectiveness in defence of its declining use at the end of this period:

"[lt is wrong] to suggest the way to improve safety is by having more inspections, when statistics tell you it can be more than ten years between visits...companies that take on the responsibility because they believe it is right...manage safety well, not those that live in fear of a visit from the inspector" (HSC Chair, House of Commons 2008: Ev.7).

Even within areas like construction, inspection came to be viewed as ineffective once the complex reality of outcome trends were reduced to the narrow terms of quantified success measures (House of Commons 2004: 4); the then-Chief Executive of HSE reported in 2008 that "the construction statistics [show]...that the number of inspectors has remained the same, and that fatalities have regrettably risen very significantly" (House of Commons 2008: Ev.7). This trend, and the failure of Fit3, confirmed the assumptions upon which this new orthodoxy was based; that the symbolic use of inspection to change social meanings around particular issues (Lessig 1995) was doomed to failure, and that the only way to understand the value of regulation was in economic terms.

\section{The Fourth Frame: Risk and Risk-Tolerance}

The importance attached to issues of expertise, efficiency, and effectiveness in riskbased inspection has, in the last ten years or so, given way to an approach which involves making more explicitly normative value judgements about regulated risks, and which implies that there are areas of risk which ought not to be regulated via inspection. Dodds (2006) has referred to this as a shift from 'better regulation' to 'risk-tolerant deregulation', that is, to setting limits on the use of intrusive tools like inspection according to the application of categorical criteria about what types of risk ought and ought not to be regulated. These decisions involve determining areas where intervention is considered 'rational', in cost-benefit terms, but also those where risks 'ought' to be tolerated for the wider benefit of society (2006: 534), because it is connected to the creation of opportunities for innovation, personal or economic growth, and the development of new markets. Risk is thus recast as a positive feature of contemporary society, rather than an undesirable side-effect of business or social activity. At this fourth stage of meaning-construction, an expressive role for risk-based regulation was embedded, but in relation to an 
economically-rational approach to public policy which saw regulatory intervention as “an always regrettable means of correcting market failure” (Prosser 2010: 1).

The 2005 Hampton Review laid the foundations for this approach, identifying the need to reduce "unnecessary inspections", which are costly, inflexible, inefficient, and constitute a "barrier to growth" (2005: 25-27). While Hampton recommended the use of risk assessment to target inspection, he did not define the basis on which risks should be calculated as high or low. This priority-setting was deferred to subsequent forums such as the Rogers Review of Local Authority enforcement, which graded topics of enforcement according to the likelihood and severity of harm (risk), plus consideration of public and political priority (2007: 36-43). The consequences of this approach have included a decline of $95 \%$ in rates of Local Authority inspection since 2009-10 (HSE 2014b: 2), which also reflects the climate of austerity within British politics during this period. This tied into the pursuit of a broader political narrative equating risk with progress and social freedom, and precaution with irrationality and political illiberalism (Dodds 2006: 535), and which insisted on the use of market-oriented, quantified approaches to regulatory decisionmaking (Black 2005; Rothstein et al. 2013). While decision-making was still couched in the technical, procedural language of scientific risk-assessment, the weighting of these risks was increasingly undertaken via reference to a wider range of political interests, in particular, those relating to the maintenance of values of self-reliance, non-interference, and anti-interventionism within market settings (Almond 2015; Tombs \& Whyte 2010). Health and safety regulation, in particular, was characterised by critics as a regulatory system that encouraged illegitimate intervention in the private lives of individuals, and which placed unjustifiable burdens on business.

This political narrative underpinned the subsequent drawing of 'risk-based' distinctions between industries where regulation should and should not occur. Policy reviews recommended that 'low-hazard' workplaces (shops, offices, schools, public spaces: Young 2010: 28), self-employed workers, and areas of unquantified 'hazard', should be taken outside the scope of formal inspection (Löfstedt 2011: 43), not because inspecting them was inefficient per se, but because the values embodied in this type of workplace were not normatively compatible with those of state-led regulatory oversight. These distinctions were embedded via the sorting of the regulated population into risk categories ('high risk areas', 'areas of concern', and 
'low-risk areas') and focusing attention only onto the first of these (DWP 2011: 9). This differentiation process was based upon assessment of sectoral hazard levels, with 'high risk' including the construction, waste management, and manufacturing sectors, and the now-uninspected 'areas of concern' including quarries, agriculture, transport, and health and social care. It was not that these were sectors where significant hazards did not arise ${ }^{4}$; rather, inspection was deemed to be "unlikely to be effective" (2011: 9), leaving issues of significant risk outside the scope of inspection:

"[In] 2011...they stopped proactively inspecting schools, so schools know they're never going to receive a visit from HSE...we're particularly concerned about that in relation to asbestos. It's difficult to think how you can make up for that" (National Union of Teachers health and safety lead, 2000s-2010s: para.96)

In cases like asbestos in schools, there was a shift towards issue-led inspection, targeted in a manner akin to the risk-activist frame (HSE 2014a: 10), but here, the degree of specificity around 'non-tolerated' risk was such that it differentiated them entirely from other risks, reinforcing the exceptionalism of inspection.

The Government's three-category model (DWP 2011) interpreted 'risk-based' practice in a distinctive way, defining whole sectors as meriting inspection, or not. This mean that by $2014,51 \%$ of proactive inspections were concentrated in the construction industry, and $37 \%$ in manufacturing, with other areas receiving almost none (HSE 2014a: 12). Rather than responsiveness to the features of the individual workplace, including specific hazards and safety performance, decisions about targeting were based on a conception of 'risk' calculated according to aggregated expectations of outcome, rather than individual factors. On this level, it was much more akin to conceptions of 'actuarial' risk encountered in areas like insurance (Ewald 2002; Feeley \& Simon 1992). It was also reflective of a conception of the instrumental value of inspection; agriculture, although high-risk, is a diffuse industry, commonly made up of small undertakings scattered across the countryside, and so inspection is less likely to bear fruit:

"the role of Regulator is to...change behaviours so there is less likely to be market failure...It's difficult to get that into the agriculture sector, for example,

\footnotetext{
${ }^{4}$ Indeed, HSE statistics show that these areas have some of the highest rates of work-related injury and illness in the UK: http://www.hse.gov.uk/statistics/industry/index.htm
} 
which is much more dispersed...you can't get the 20 biggest farmers around the table and know you're speaking to people who are influencing $40 \%$ of the industry." (HSE Deputy Chief Executive, 2000s-2010s: para.31)

This highlights one key reason for the move towards risk-tolerance, and which shows some of the continuities between the different framing periods: cuts to regulatory capacity had placed a premium on extracting the greatest effect from limited resources. While this is something regulators often avoid admitting (House of Commons 2008: Ev.6-8), it is also a persistent reality of the political context, whether viewed ideologically (as in the case of the NPM) or pragmatically, as a response to the changing economic context.

But at the same time, however, the risk-tolerant framing of inspection goes beyond this, crystallising a particular conception of the regulatory role and its relation to other social values and interests. Regulatory decision-making, while framed as risk-based, had become increasingly political, giving effect to a particular balance of competing interests (those of market freedom and of interventionist control) which framed regulation in narrow, particular terms (Almond 2015). It served, on one level, as a restatement of an orthodoxy, often repeated across the decades in various forms by different stakeholders, that 'the duty-holder, and not the regulator, owns the risk' (HSE Director-General, 1980s-1990s: para.89; HSE Deputy Chief Executive, 2000s2010s: para.20; Robens 1972: para.41). On this view, the primary responsibility for regulatory oversight lies with the economic self-interest and market-correcting tendencies of the regulated population, to be determined on the basis of their own rationality. The settlement of interests to take place around issues of risk should be defined via reference to politically-valorised social values (of economic selfdeterminism), or tightly-defined measurements of cost and benefit; consideration of other factors would fall outside the scope of the regulatory role as currently defined (Almond 2015).

Rather than aiding them in acting expertly, effectively, and efficiently, risk-based tools thus act to curtail the competence and scope of the regulator. As the last interview quotation makes clear in the case of agriculture (HSE Deputy Chief Executive, 2000s-2010s: para.31), regulators increasingly view themselves as custodians of market-corrective procedures. The range of contexts where it is legitimate for them to engage with duty-holders in pursuit of welfarist goals is 
narrowed, and this role is increasingly outside the scope of the regulatory orthodoxy. This has been one part of a broader redefinition of the regulatory role in economic terms, as a matter of commercial service provision; regulators have encountered "pressures to become...more like the organisations they regulate...[they] have necessarily become risk-based, because this is what is expected" (Power 2007: 91). For HSE, this has meant being pushed towards the use of licensing-type arrangements ('fee for intervention'5), whereby the costs of inspection are increasingly recovered from those who are inspected, and lower-risk duty-holders are afforded the chance to 'purchase' inspector input as a commercial service:

"It is right that we focus [our] limited resources on the people that are most in need...some of the better people will get less of our attention, but if they value our attention and are prepared to pay for it that's something we can look at. There are risks in terms of managing that...but there are certainly people that want our advice” (HSE Deputy Chief Executive, 2000s-2010s: para.61)

On this view, inspection, in its traditional form, is reserved only for the 'deserving' regulated (those in high-risk areas, those who are expected to breach the law). For all others, it is positioned as an exceptional and voluntary measure, whose value and desirability is determined by reference to the individual economic interests of the parties involved, rather than any conception of the regulatory 'good'.

The other impact of risk-tolerance is on the distribution of responsibility. As Rothstein et al. observe (2013: 221), risk modelling places limits on expectations and accountability in relation to 'acceptable' risks. By setting a range of industries outside the scope of inspection, government accountability for failures in these areas is avoided, and areas of potential difficulty that may challenge regulatory performance and pose risks to the delivery of regulatory objectives are circumvented (Black 2005: 515; Power 2007: 89). The healthcare sector was one where this tendency was observed:

"Our concern is about health being a low risk sector [with] less inspection going on...it's one of those issues they probably don't want to deal with because it's not black and white" (Healthcare Trade Union health and safety lead, 2000s-2010s: para.94)

\footnotetext{
${ }^{5}$ http://www.hse.gov.uk/fee-for-intervention/
} 
There is thus a tendency for risk-based practices to have a 'smoothing' effect, that is, for regulators to be incentivised to focus their attentions onto their 'core business', and to overlook areas that detract from their operational performance goals (Black \& Baldwin 2012; Power 2007: 91; Rothstein et al. 2013: 218). As the orthodoxy around regulation becomes one in which regulators are pushed to think and act more like commercial, economic organisations, risk-based practices provide an objective, metrically quantified basis on which to make and defend choices about priority and value. As has been observed elsewhere (Baldwin and Black 2016; Dodds 2006; Hutter 2005), risk-based approaches are regularly used to rationalise political forms of regulatory decision-making, while simultaneously obscuring the political nature of those decisions. In the case of inspection, this contributes to a broader project of redefining health and safety regulation's role in modern society (Almond 2015).

It is an irony, then, that the preference for this kind of quantified decision-making is itself an elective choice, which policymakers are willing to discard when expedient:

"[The Minister] said, 'We've got to have a risk-based approach and it must be evidence-based. The biggest risk we face is that we're becoming hopelessly risk-averse'. So I said, 'But where's the evidence for that?'. 'Oh, we don't need evidence for that,' he said, 'everybody knows it'." (Safety Industry Body policy lead, 1994-2014: para.43)

In sum, risk-based rationality has been chosen as a model to apply in pursuit of a political process of narrowing the ambitions of the regulatory system, as aspirations towards universal coverage are set aside in favour of a more individualized and rationalized set of guiding assumptions (Almond 2015: 221). The most distinctive contribution made by the risk-tolerant frame has been to harness the definition and measurement of risk to the making of categorical value judgements about where inspection ought to occur. While Government rhetoric has framed this process in ideological terms as a battle against 'red tape', the use of inspection as a 'risktolerant' measure has been equally important in establishing the new orthodoxy of regulatory intervention as something which is legitimately confined to a narrow range of 'deserving' duty-holders.

\section{Conclusions}


Over the last fifty years, health and safety inspection policy in the UK has shifted towards the pursuit of new goals of devolved responsibility, risk-based targeting, and efficiency gains, and there has been a move away from generalist inspection. A new 'orthodoxy of meaning' around inspection has emerged, which has established the use of this tool as exceptional, and subject to assessment as 'inefficient' and 'ineffective' according to the prevailing framework for value judgement. The changing notions of 'risk-based' regulation, sketched here, have each contributed to a process of 'reregulation of social meaning' (Lessig 1995), embodying in turn values of expertise, efficiency, effectiveness, and exceptionalism. This has culminated in a risk-tolerant dynamic, which uses the logic of risk-based decision-making to draw wide-ranging, categorical differences between areas where inspection is and is not suitable or deserved, and which sees inspection increasingly as a subject of marketbased decision-making. Cumulatively, this has led to the development of a new orthodoxy around inspection, dominated by economic rationality and the consideration of efficiency to the exclusion of other criteria. The balance between instrumental and symbolic uses of inspection identified by Hutter (1986) has been settled in favour of instrumentalism, and the contested political climate has led to a narrower conception of where, when and how inspection should be used.

In essence, risk-based regulation has meant different things at different times, as dictated by changing political circumstances and evolving normative conceptions of legitimacy; from being contingent on the way that inspection is done, or factors internal to the process itself, to being contingent upon the way that inspection is measured, or factors external to the process. Inspection, as a tool, has increasingly been evaluated according to an economic rationality imported from elsewhere in government, and has largely been found wanting on those terms. This has happened alongside a narrowing of the parameters of the regulatory state more generally, away from values of interventionism, universalism, and generality, and towards individualism, rationalization, and decentring (Almond 2015), so that the two tendencies are mutually reinforcing. On the one hand, inspection is a top-down, invasive tool that is difficult to reconcile with the values of this new regulatory reality, and risk-based approaches have offered a means of achieving this by placing it on a targeted, 'efficiency-centric' footing. On the other, risk-based practice has provided the 'good reasons' for this change of regulatory reality, being utilised to establish an 
underpinning commitment to economic decision-making as the cornerstones of a new 'orthodoxy of meaning' around regulation. In this way, regulatory inspection, as a process of expressive law-formation, comes to embody and entrench prevailing political values that privilege an economic view of regulation. While previous literature has tended to conceive of the incorporation of social values into regulatory processes as a potential counterweight to economic-oriented orthodoxies (Lessig 1996), this investigation has demonstrated that processes of regulatory meaningconstruction are particularly adept at producing outcomes that mirror, rather than challenge, the prevailing political climate of the day.

On one level, then, this paper lends evidential support to claims that risk-based regulatory practices are inherently political in nature, but that their apparent methodological objectivity serves to obscure this political component (such as Hutter 2005; Power 2007; Rothstein et al. 2013). On another level, however, this investigation has also shown how adept and flexible these tools are as mechanisms of political change. Because 'risk-based' is capable of meaning a range of different things in relation to regulatory practices, it gives effect to a range of different values and agendas. To this end, the pursuit of a risk-based inspection strategy has looked very different across the 40-year period surveyed in this paper. This has meant that even regulators (like HSE) who have been broadly consistent in their own approach, adhering since the 1970s to a model of targeted intervention, have been subjected to considerable pressure to change their approach so as to conform to the prevailing agendas of government. This interplay between the regulatory and the political also serves to demonstrate the significant role that questions of agency and difference play within the 'regulatory state'. As one regulator observed, ruefully, even being lauded as the originator of a policy does not preclude pressure from government, or guarantee the future ownership of that policy:

"Most of the...Better Regulation agenda has been stealing stuff that we developed....principles of transparency, targeting, consistency, proportionality, they came from us...[but] they're obviously going to look at us and challenge us" (HSE Deputy Chief Executive, 2000s-2010s: para.52)

The most significant implication of the redefinition of the meaning of 'risk-based' inspection sketched out in this paper, has been the tendency for this term to be utilised explicitly as a means of making normative choices about how far regulation 
should go. Rather than making reference to matters of expertise, efficiency, and effectiveness, however they may be evaluated, the focus has moved towards preferential value-judgements about the weighing of risk within a broader political framework. In this sense, while the procedural legitimatory norms that justified riskbased approaches (accountability, efficiency, legality: Baldwin 1995) were, in the past, politically chosen as values to pursue within public administration, the focus of this choice has increasingly shifted to the selection of the outcomes and ends that are sought, rather than the means by which they are achieved. 'Better regulation' has thus been supplanted as the essentially neutral aim of political action, and now functions as a means of achieving a broader set of political aims, namely, the redrawing of the "sometimes fragile balance between the interests of economic activity on the one hand and the public welfare on the other" (Hawkins 1984: 9). As contemporary regulatory states face up to an era of increasing challenge from political actors over the ends and goals they are seen to represent, it becomes increasingly important to acknowledge the permeability of regulatory concepts to broader political influences and social values. They must be understood not just as the outcomes of political processes, but also as tools and mechanisms through which those political processes are enacted, expressed, and entrenched.

\section{References}

Almond P (2009) The Dangers of Hanging Baskets: Regulatory Myths' and Media Representations of Health and Safety Regulation. Journal of Law and Society 36, 352-375.

Almond P (2013) Corporate Manslaughter and Regulatory Reform. Palgrave Macmillan, Basingstoke.

Almond P (2015) Revolution Blues: The Reconstruction of Health and Safety Law as 'Common-Sense' Regulation. Journal of Law and Society 42, 202-229.

Ayres I, Braithwaite J (1992) Responsive Regulation: Transcending the Deregulation Debate. Oxford University Press, Oxford.

Baldwin R (1995) Rules and Government. Clarendon Press, Oxford. 
Baldwin R, Black J (2016) 'Driving Priorities in Risk-Based Regulation: What's the Problem? Journal of Law and Society 43, 565-595.

Benford RD, Snow DA (2000) Framing Processes and Social Movements: An Overview and Assessment. Annual Review of Sociology 26, 611-639.

Bernstein PL (1996) Against the Gods: The Remarkable Story of Risk. Wiley, New York.

BRE [Better Regulation Executive] (2008) Effective Inspection and Enforcement: Implementing the Hampton Vision in the Health and Safety Executive, http://www.nao.org.uk/wp-content/uploads/2008/03/HSE Hampton report.pdf.

Better Regulation Task Force (2000) Principles of Good Regulation. (Crown, London.

Black J (2005) The Emergence of Risk-based Regulation and the new Public Risk Management in the United Kingdom. Public Law, 512-549.

Black J (2008) Constructing and Contesting Legitimacy and Accountability in Polycentric Regulatory Regimes. Regulation \& Governance 2, 137-164.

Black J, Baldwin R (2010) Really Responsive Risk-Based Regulation. Law \& Policy $32,181-213$.

Black J, Baldwin R (2012) When Risk-Based Regulation Aims Low: Approaches and Challenges. Regulation \& Governance 6, 2-22.

Cabinet Office (1999) Modernising Government. HMSO, London.

Dawson S, Willman P, Clinton A, Bamford M (1988) Safety at Work: The Limits of Self-Regulation. Cambridge University Press, Cambridge.

Dodds A (2006) The Core Executive's Approach to Regulation: From 'Better Regulation' to 'Risk-Tolerant Deregulation'. Social Policy \& Administration 40, 526-542.

DEP [Department of Employment and Productivity] (1968) Annual Report of HM Chief Inspector of Factories, 1967, Cmnd. 3745. HMSO, London. 
DETR [Department of Environment, Transport and the Regions] (2000) Revitalising Health and Safety: Strategy Statement. Crown, London.

DWP [Department of Work and Pensions] (2011) Good Health and Safety, Good for Everyone, http://www.dwp.gov.uk/docs/good-health-and-safety.pdf.

Employment Committee (1988) The Work of the Health and Safety Commission and Executive, minutes of evidence 20 January 1988, HC 267. Crown, London.

Entmann RM (1993) Framing: Toward Clarification of a Fractured Paradigm. Journal of Communication 43, 51-58.

Etienne J (2015) The Politics of Detection in Business Regulation. Journal of Public Administration Research and Theory 25, 257-284.

Ewald F (2002) The Return of Descartes's Malicious Demon: An Outline of a Philosophy of Precaution. In Baker T, Simon J (eds.) Embracing Risk: The Changing Culture of Insurance and Responsibility, pp. 273-302. University Of Chicago Press, Chicago.

Feeley M, Simon J (1992) The New Penology: Notes on the Emerging Strategy of Corrections and its Implications. Criminology 30, 449-474.

Gamble A (1994) The Free Economy and the Strong State: The Politics of Thatcherism (2nd ed.). Macmillan, London.

Gunningham N, Grabosky P (1998) Smart Regulation: Designing Environmental Policy. Oxford University Press, Oxford.

Gunningham N, Johnstone R (1999) Regulating Workplace Safety: Systems and Sanctions. Oxford University Press, Oxford.

Hawkins K (1984) Environment and Enforcement: Regulation and the Social Definition of Pollution. Clarendon Press, Oxford.

Hawkins K (2002) Law as Last Resort: Prosecution Decision-Making in a Regulatory Agency. Oxford University Press, Oxford.

Hawkins K, Hutter B (1993) The Response of Business to Social Regulation in England and Wales: An Enforcement Perspective. Law \& Policy 15, 199-217. 
HM Government (1985) Lifting the Burden, Cmnd.9571. Crown, London.

HM Government (1986) Building Businesses...Not Barriers, Cmnd.9794. Crown, London.

Hood C (1991) A Public Management for All Seasons?. Public Administration 69, 319.

Hood C, Rothstein H, Baldwin R (2001) The Government of Risk: Understanding Risk Regulation Regimes. Oxford University Press, Oxford.

House of Commons (2004) Committee of Public Accounts, Health and Safety Executive: Improving Health and Safety in the Construction Industry, FiftySecond Report of Session 2003-4 [HC 627]. HMSO, London.

House of Commons (2008) Work and Pensions Select Committee, 02 April 2008: The Role of the Health and Safety Commission and the Health and Safety Executive in Regulating Workplace Health and Safety: Third Report of Session 2007-08 [HC 246], vol.2. HMSO, London.

HSE (1980) Health and Safety, Manufacturing and Service Industries, Report for 1978. HMSO, London.

HSE (1981) Health and Safety, Manufacturing and Service Industries, Report for 1979. HMSO, London.

HSE (1988) The Tolerability of Risks from Nuclear Power Stations. HMSO, London.

HSE (1997) Successful Health and Safety Management [HSG65]. HSE, London.

HSE (2014a) The Health and Safety Executive Annual Report and Accounts 2013/14 [HC228] (http://www.hse.gov.uk/aboutus/reports/1314/ar1314.pdf).

HSE (2014b) HELA Data Collection-Analysis of LAE1 2013/14 Data from Local Authorities [Paper H17/01]

(http://www.hse.gov.uk/aboutus/meetings/committees/hela/310714/datacollection\%E2\%80\%93analysis.pdf).

Hutter B (1986) An Inspector Calls: The Importance of Proactive Enforcement in the Regulatory Context. British Journal of Criminology 26, 114-128. 
Hutter B (1989) Variations in Regulatory Enforcement Styles. Law \& Policy 11, 153174.

Hutter B (1997) Compliance: Regulation and Environment. Clarendon Press, Oxford.

Hutter B (2005) The Attractions of Risk-Based Regulation: Accounting for the Emergence of Risk Ideas in Regulation. CARR Discussion Paper no.33, http://www.lse.ac.uk/accounting/CARR/pdf/DPs/Disspaper33.pdf.

Hutter B, Lloyd-Bostock S (1990) The Power of Accidents: The Social and Psychological Impact of Accidents and the Enforcement of Safety Regulations. British Journal of Criminology 30, 409-422.

Kloman HF (1990) Risk Management Agonistes. Risk Analysis 10, 201-205.

Hutter B, Manning P (1990) The Contexts of Regulation: The Impacts Upon Health and Safety Inspectorates in Britain. Law \& Policy 12, 103-136.

Lessig L (1995) The Regulation of Social Meaning. University of Chicago Law Review 62, 943-1045.

Lessig L (1996) Social Meaning and Social Norms. University of Pennsylvania Law Review 144, 2181-2189.

Löfstedt R (2011) Reclaiming Health and Safety for All: An Independent Review of Health and Safety Legislation [The Löfstedt Review]. Crown, London.

Lo CWH, Fryxell GE, Van Rooij, B. (2009) Changes in Enforcement Styles among Environmental Enforcement Officials in China. Environment and Planning A, $41,2706-2723$

Mascini P (2013) Why was the Enforcement Pyramid so Influential? And What Price was Paid?. Regulation \& Governance 7, 48-60.

Mascini P (2016) Ethnographic Portraits of Regulatory Inspectors on the Job: Implications for Oversight Policy. In van Slyke S, Benson M, Cullen FT (eds.) The Oxford Handbook of White-Collar Crime, pp. 521-539. Oxford University Press, Oxford. 
Mascini P, van Wijk E (2009) Responsive Regulation at the Dutch Food and Consumer Product Safety Authority: An Empirical Assessment of Assumptions Underlying the Theory. Regulation \& Governance 3, 27-47.

McAllister LK (2010) Dimensions of Enforcement Style: Factoring in Regulatory Autonomy and Capacity. Law \& Policy 32, 61-78.

Mendeloff J, Gray WB (2005) Inside the Black Box: How Do OSHA Inspections Lead to Reductions in Workplace Injuries? Law \& Policy 27, 219-37.

Moran M (2003) The British Regulatory State: High Modernism and Hyper Innovation. Oxford University Press, Oxford.

OECD (2012) Recommendations on Regulatory Policy and Governance (http://www.oecd.org/governance/regulatory-policy/49990817.pdf).

O'Malley P (2004) The Government of Risks. In Sarat A (ed.) The Blackwell Companion to Law and Society, pp.292-308. Wiley, London.

Pildes RH, Sunstein CR (1995) Reinventing the Regulatory State. The University of Chicago Law Review 62, 1-129.

Pires RR (2011) Beyond the Fear of Discretion: Flexibility, Performance, and Accountability in the Management of Regulatory Bureaucracies. Regulation \& Governance 5, 43-69.

Power M (1997) The Audit Society: Rituals of Verification. Oxford University Press, Oxford.

Power M (2004) The Risk Management of Everything. Demos, London.

Power M (2007) Organized Uncertainty: Designing a World of Risk Management. Oxford University Press, Oxford.

Prosser T (2010) The Regulatory Enterprise: Government, Regulation, and Legitimacy. Oxford University Press, Oxford.

Rhodes G (1981) Inspectorates in British Government: Law Enforcement and Standards of Efficiency. Allen and Unwin, London. 
Lord Robens (1972) Safety and Health at Work: Report of the Committee 1970-72 (The Robens Report). HMSO, London.

Rogers P (2007) National Enforcement Priorities for Local Authority Regulatory Services [The Rogers Review]. HMSO, London.

Rothstein H, Irving P, Walden T, Yearsley R (2006) The Risks of Risk-based Regulation: Insights from the Environmental Policy Domain. Environment International 32, 1056-1065.

Rothstein H, Borraz O, Huber M (2013) Risk and the Limits of Governance: Exploring Varied Patterns of Risk-Based Governance across Europe. Regulation \& Governance 7, 215-235.

Sparrow M (2000) The Regulatory Craft. Brookings Institution Press, Washington, D.C.

Sunstein CR (1996) On the Expressive Function of Law. University of Pennsylvania Law Review 144, 2021-2053.

Thornton D, Gunningham NA, Kagan RA (2005) General Deterrence and Corporate Environmental Behavior. Law \& Policy 27: 262-88.

Tombs S, Whyte D (2010) A Deadly Consensus: Worker Safety and Regulatory Degradation under New Labour. British Journal of Criminology 50, 46-65.

Tombs S, Whyte D (2013) Transcending the Deregulation Debate? Regulation, Risk, and the Enforcement of Health and Safety Law in the UK. Regulation \& Governance 7, 61-79.

Walters D, Johnstone R, Frick K, Quinlan M, Baril-Gingras G, Thébaud-Mony A (2011) Regulating Workplace Risks: A Comparative Study of Inspection Regimes in Times of Change. Edward Elgar, Cheltenham.

Warburton RM (1980) The Factory Inspectorate: Its Changing Roles. Employee Relations 2, 6-11.

Lord Young (2010) Common Sense, Common Safety [The Young Review]. Crown, London. 